\title{
List of dictionaries
}

Grinchenko B.D. Slovar' ukrainskogo yazyka [Dictionary of Ukrainian Language]. In 4 vols. Kiev, 1958.

Slovar' russkogo yazyka [Dictionary of Russian Language]. In 4 vols. Moskva, 19571961. (MAS)

Slovnik ukrains'koi movi [Dictionary of Ukrainian Language]. Kiev, 1970-1980. (SUM)

\section{СТРАТЕГИИ И ТАКТИКИ ПОЛИТИЧЕСКОЙ МАНИПУЛЯЦИИ В СМИ}

\section{В.А. Голянская, Н.В. Мельник}

Ключевые слова: политическая лингвистика, манипуляция, стратегии, тактики, интернет-комментарий.

Keywords: political linguistics, manipulation, strategics, tactics, Internet comment.

\section{DOI 10.14258/filichel(2019)3-03}

Данное исследование выполнено на стыке лингвополитологии, лингвопрагматики, теории обыденного языкового сознания, интернетлингвистики, стилистики и теории текста и посвящено исследованию стратегий и тактик манипуляции массовым сознанием в виртуальных средствах массовой информации и оценке их эффективности.

В современном мире сложно переоценить воздействие СМИ на сознание человека. Однако при таком большом потоке информации человеку порой трудно проверить ее достоверность и критически оценить способ представления. У медиа появилась возможность формировать политические, ценностные и другие общественные установки, вследствие чего стали говорить о таком явлении, как манипуляция массовым сознанием.

Главным инструментом общения выступает язык, поэтому именно языковая манипуляция является самым распространенным типом манипуляции. Этому способствует и то, что язык предоставляет множество инструментов для воздействия на аудиторию. Несмотря на

\footnotetext{
${ }^{1}$ Исследование выполнено при финансовой поддержке РФФИ в рамках научного проекта № 19-012-00522.
} 
то, что СМИ заявляют о беспристрастности, вряд ли это возможно изза установки редакции, личностных особенностей журналиста и т.п. О.Н. Быкова пишет: «Ни для кого уже не секрет, что функции СМИ и механизмы воздействия на массовую аудиторию примерно одни и те же в любом обществе» [Быкова, 2012, с. 124]. Однако исследователь отмечает, что данная проблема в современной лингвистике изучена мало. В основном представлены работы по манипулятивному потенциалу текстов, созданных кандидатами на власть или уже господствующей элитой. В данной работе будет рассматриваться обратная сторона - проблема манипуляции в СМИ, когда именно через медиа реализуется попытка дискредитации власти.

Существует много определений термина «языковая манипуляция», мы вслед за Г.А. Копниной понимаем под ней «разновидность манипулятивного воздействия, осуществляемого путем искусного использования определенных ресурсов языка с целью скрытого влияния на когнитивную и поведенческую деятельность адресата» [Копнина, 2012, с. 24].

В целом проблемой манипуляции начали интересоваться еще в Древней Греции, в эпоху расцвета демократии. С падением демократии менялось и отношение к риторике. В современной лингвистике много работ, в которых изучается феномен манипуляции. Например, с точки зрения психологического аспекта манипуляцию рассматривают Е.Л Доценко [Доценко, 1996], С.Г. Кара-Мурза [Кара-Мурза, 2001], В.П. Шейнов [Шейнов, 2001], В.Н. Куницына, Н.В. Казаринова [Куницына, Казаринова, Погольша, 2001]. Они исследуют механизмы манипуляции, как наше сознание на нее реагирует, как защититься от воздействия и т.д. Изучением языкового воздействия занимаются О.С. Иссерс [Иссерс, 2011], Г.А. Копнина [Копнина, 2012], Л.Ю. Иванов [Иванов, 2003], И.В. Сентенберг, В.И. Карасик [Сентенберг, Карасик, 1993] и другие. Манипулированием же в политическом дискурсе отечественные ученые начали активно заниматься в конце XX - начале XXI века. Это, в первую очередь, связано со сложившейся в России политической ситуацией. Среди исследователей, которые занимаются изучением манипуляции в политическом дискурсе, можно выделить Н.Э. Гронскую [Гронская, 2005] и О.Л. Михалеву [Михалева, 2009].

Материалом исследования послужил текст новости «Путин подписал закон о свободном сборе валежника» с сайта Lenta.ru, а также комментарии к ней. Lenta.ru - это официально зарегистрированное средство массовой информации, новость о сборе валежника находится в разделе «Политика», поэтому в данном случае можно говорить о 
языковом манипулировании массовым политическим сознанием, которое имеет важную особенность: коммуникативный акт является неполным и нацелен на одностороннее воздействие.

В данной статье будут представлены результаты выделения стратегий и тактик политической языковой манипуляции, а также оценена их эффективность, исходя из комментариев читателей. Таким образом, исследование выполнялось в два этапа: на первом детальному лингвостилистическому анализу был подвергнут исходный текст, направленный на дискредитацию власти с помощью применения различных манипулятивных тактик, а на втором этапе посредством обращения к реакции читателей, опредмеченной в интернеткомментариях на текст новости, оценивалась эффективность использованных тактик.

Представим результаты первого этапа исследования. Новость была опубликована на сайте Lenta.ru 18 апреля 2018 года:

\section{Путин подписал закон о свободном сборе валежника}

Президент России Владимир Путин подписал закон, который позволяет россиянам свободно собирать валежник в лесу для собственных нужд. Соответствующий документ опубликован на официальном портале правовой информации.

Закон, принятый Госдумой 3 апреля 2018-го, вступит в силу с 2019 года. Поправки внесены в Лесной кодекс. Они позволят заготавливать и собирать упавшие на землю стволь деревьев или их части, сучья и ветви для собственных нужд. Согласно документу, валежник относится к недревесным лесным ресурсам.

Первыц замруководителя фракции «Единой России» Андрей Исаев, комментируя инициативу разрешить свободный сбор валежника, отметил, что у него просто радуется сердце. Принятие законопроекта порадовало многих пользователей сети. По их словам, Госдума наконец что-то разрешает, а не запрещуает. «Всего 10 лет прошло, а уже разрешили населению валежник собирать!» отмечает пользователь Михаил Светлов. "Валежник-начиональное достояние! Мечты сбываются!» - говорится в аккаунте в Twitter «Валежник Наш» (Lenta.ru. 18.04.2018).

Способ подачи информации стандартный для новости - принцип перевернутой пирамиды. Суть данного способа заключается в том, что в тексте можно выделить наиболее и наименее значимые части. Новость начинается с заголовка, в котором подана главная идея, суть заметки. Далее идет так называемый лид - более подробная часть по сравнению с заголовком, но в нем также подана новая информация в сжатом виде. За ним следует основная часть, или «тело новости» - 
информация принимает более узкий, специализированный характер, уточняются данные, озвученные в заголовке и лиде. Стоит отметить, что чем ближе к концу новости, тем менее значимы представленные сведения.

Отметим, что в исследуемом тексте информация манипулятивного характера вводится имплицитно. привлекательности именно такого способа пишет Ю.К. Пирогова [Пирогова, 2001]. Так как информация, поданная скрыто, не осознается адресатом, то он не может ее критически осмыслить. Также знания представлены не в готовом виде, соответственно, их надо извлечь, изза подключения подобного механизма человек легко запоминает полученную выводным путем информацию. Еще одно преимущество уход журналиста от ответственности в связи с «Законом о рекламе».

Обратим внимание на заголовок новости: «Путин подписал закон о свободном сборе валежника». Представляется немаловажным то, что здесь используется активный залог в качестве речевого средства манипуляции. То есть автор статьи подчеркивает, что ответственность за данное решение лежит на Владимире Путине. На первый план выходит не событие, а лицо, принимающее решение, в связи с этим мы считаем возможным выделить тактику персонификации. Отметим, что здесь и далее манипулятивные тактики были выведены из анализа материала. Первым называется имя российского лидера, соответственно, оно стоит в самой сильной позиции. В то же время ставится акцент на том, что именно президент принимает решения относительно законов, хотя до этого документ проходит довольно много стадий подготовки. И так как закон, скорее, ироничный и достаточно мелкий для главы государства, все гневные реакции читателей будут направлены именно на того человека, в лице которого власть персонифицирована. Уже в заголовке мы видим оппозицию «серьезность - несерьезность», так как словосочетание «закон о сборе валежника» соединяет в себе значительное как для сферы права, так и для общественной жизни понятие «закон» и обыденное «валежник». Прилагательное «свободный» также представляет интерес. Оно выстраивает некоторую градацию законов, показывает, что некоторые документы являются полностью разрешающими, а некоторые частично.

Лид на данном сайте не отделен от «тела новости», поэтому он воспринимается как первый абзац основного текста. Как и предполагает принцип перевернутой пирамиды, лид повторяет информацию, поданную в заголовке, немного расширив ее. Начинается он также с наименования президента РФ, однако теперь называется не 
только имя Путина, но и должность, что ставит акцент на официальности мероприятия (подписание закона). Лексема «позволяет» подчеркивает дистанцию между тем, кто позволяет, подписывает законы (в данном случае это Владимир Путин), и теми, кому разрешается выполнять определенные действия. Выбор слова «россияне» также представляется интересным. Это дистанцирует граждан РФ и других государств, а также российскую власть от народа. Автор текста отгородил Путина от остальных россиян, как бы вывел его за границы этого понятия, выбрав такую лексему. Кроме того, здесь также используется активный залог, который сосредоточивает внимание на лице, а не на действии. Создается некая триада «свои 1»«свои 2»- «чужие». В качестве «своих 1» выступают россияне, обычные люди, которым как раз разрешают и позволяют. «Свои 2» же - это власть: в данном случае исключительно Путин, ни о каких других ее источниках из лида мы не узнаем. Если в классической дихотомии «свои - чужие» мир представляется, по О.С. Иссерс, черно-белым [Иссерс, 2011], то в данном тексте можно говорить о тактике «серого мира». Здесь представляется в невыгодном свете не только власть, но и граждане, которые, как мы далее увидим, могут только шутить на эту тему, но не могут ничего поменять, оставаясь в невыгодном положении. Также лексема «россияне» автоматически выделяет людей, находящихся за пределами РФ, соответственно, и их другую жизнь. В тексте упоминается, для каких нужд разрешается сбор валежника, то есть подчеркиваются ограничения законодательства, и оказывается, что словосочетания «свободный сбор» и «для собственных нужд» иллюстрируют некую ограниченную свободу. Далее журналист ссылается на авторитетный источник данных - официальный портал правовой информации. В очередной раз тексту придается некая официальность, серьезность.

Рассмотрим второй абзац новости. Появляется предыстория принятия закона, поясняется, что его приняла Госдума. То есть Путин подписывает, говорит последнее слово, однако инициатором был не он. Тем не менее Госдума упоминается в слабой текстовой позиции. Приводятся сроки вступления закона в силу. Заметим, что от его окончательного принятия до вступления в силу остается восемь месяцев - довольно большой срок. Так Lenta.ru имплицитно показывает неторопливость властей хоть каким-то образом облегчить жизнь россиян (так как закон все же разрешающий). В описании валежника также применяется тактика низвержения. Это демонстрирует выбор лексических средств, с помощью которых описывается валежник: «упавшие ветки», «их части», «сучья». Люди 
узнают, что, если пересказать закон простым языком, то россиянам разрешили собирать упавшие на землю ветки, чтобы растопить печь, например (личные нужды). Под таким углом зрения документ выглядит унизительным. Во втором абзаце повторяется лексема «позволят», что говорит о закономерности. Она подчеркивает нелицеприятное положение россиян: не люди смогут собирать валежник, а поправки в закон позволят это делать.

Обратимся к последнему абзацу новости (концовка - сильная позиция текста), содержащему наибольший манипулятивный потенциал. В нем приводятся мнения замруководителя фракции «Единая России» Андрея Исаева и пользователей Сети. Данная часть текста самая саркастичная. Журналист напрямую не высказывает свое мнение по поводу подписанного закона, однако его можно понять, исходя из выбранных для публикации комментариев. Первый - это мнение депутата Андрея Исаева. По тексту не совсем понятно, говорит он серьезно или шутит. Однако в любом случае Андрей Исаев выглядит не в лучшем свете: если он говорит серьезно, то кажется некомпетентным, а если шутит, то мысль кажется издевательством. Обратим внимание и на то, что в новости появляется еще один представитель власти, помимо Путина. Выдержки же из аккаунта в Twitter - это сарказм. Опять же, акцент сделан на разрешающем характере закона, теперь открыто, но руками неизвестного человека из Сети, а не как в заголовке и лиде - имплицитно. Обозначим такой прием тактикой сокрытия. Журналист как бы подает объективную информацию, цитирует источник, но на самом деле автор лишь прячется за мнением Михаила Светлова, ведь невозможно определить, есть ли такой человек на самом деле и комментировал ли он новость о валежнике. Однако если мнение правдиво, то показательно, что именно его сотрудник издания выбрал в качестве иллюстративного материала. Примечательно, что заканчивается новость тактикой низвержения измененными прецедентными текстами: из “"Газпром” - достояние России! Мечты сбываются!» в «Валежник - национальное достояние! Мечты сбываются!» и из «Крым наш» в «Валежник наш». Приведены не просто знакомые всем тексты. Первый является рекламой крупнейшей российской энергетической компании, важно, что она принадлежит государству. В приведенном отрывке идет апелляция к чувствам и эмоциям людей, получается ряд по аналогии: «Газпром Россия - мечта», то есть с помощью государства исполняются мечты. Второй текст еще более важный: присоединение Крыма оценивается некоторыми как обретение Россией прежней мощи. Таким образом, можно говорить о том, что высмеиваются некие национальные идеи. 
Важно само информирование читателей о появлении у валежника собственного аккаунта в соцсети: во-первых, это показывает резонанс, который вызвал данный закон; во-вторых, иллюстрирует саркастическое отношение россиян к официальному документу.

Таким образом, можно сделать вывод об используемой в тексте стратегии дискредитации действующей власти. Журналист увеличивает дистанцию между властью и народом, персонифицирует власть, приводит саркастические мнения по поводу нового закона, высмеивает, опять же имплицитно, национальные идеи. Все это работает на снижение образа российского госаппарата. Стратегия реализуется с помощью грамматических и лексических речевых средств манипуляции, которые упоминались выше. К ним относятся выбор залога, лексем, изменение прецедентных текстов, саркастические высказывания.

Представим результаты второго этапа исследования, в рамках которого предполагалась оценка эффективности примененных манипулятивных тактик. Для этого обратимся к комментариям к новости «Путин подписал закон о свободном сборе валежника», их на сайте Lenta.ru - 416.

Большинство комментаторов среагировали на упоминание президента России. Всего выделено 95 реакций, которые содержали в себе какое-либо наименование президента. Рассмотрим их подробнее. Безусловно, ядерными наименованиями лидера РФ были официально принятые - «президент» («Какой у нас добрый президент, скоро и колоски разрешит собирать», «чудной у нас президент, однако:)»), «Путин» («Великой стране - великий закон! Путин - выдающийся политический деятель!») (Lenta.ru. 18.04.2018), «Глава государства» («мелковат закон для главы государства. это и минлесхоз мог спокойно вывести на обозрение») (Lenta.ru. 18.04.2018), «Владимир Путин» («<..> В России указом лучшего президента в мире Владимира Путина, гражданам страны разрешили сбор хвороста для отапливания домов, в которых никогда не будет теплой воды, отопления, газа») (Lenta.ru. 18.04.2018). Если рассматривать их вне контекста, то можно говорить о нейтральности, однако из примеров мы видим, что комментарии либо ироничные, либо саркастичные, либо отрицательные.

Также для упоминания президента использовались различные вариации его имени: «В.В.» («Ox как неожиданно!!! В.В. вашей щедрости просто нет границ!!! Теперь мы можем питаться хворостом и корой! Силь Небесные!») (Lenta.ru. 18.04.2018), «Вован», «Володька», «Вова», «ВВП», «валотька» («Следующий указ 
валотьки будет про разрешение на сбор кизяка)») (Lenta.ru. 18.04.2018), «Володя», «вовандер», «Путя», «п-утен» («n-утен как всегда забыл про каклятские приоритеты. не ваш он иарь однозначно») (Lenta.ru. 18.04.2018). Отметим, что самым частотным является сокращенный вариант имени - Вова.

Одним из самых распространенных вариантов наименования политика является «царь» и сопутствующие ему «Солнцеликий», «кормилец», «батюшка», «Отец родной», «благодетель», «Государь»: «СЛАВА ЦАРЮ БАТЮШКЕ!!!»; «Царь особым указом холопам разрешил дрова собирать. Этопабеда!» (Lenta.ru. 18.04.2018). С помощью данных словоформ комментаторы саркастично связали президента демократической страны (РФ) с прошлой царской властью, подчеркивая дистанцию между элитой и простыми гражданами. Как мы видим, читатели подхватывают и транслируют в ответ саркастичный тон, который журналист задает в конце новости.

Встречаются не только ироничные, но и оскорбительные наименования В.В. Путина, среди них можно выделить «гад» («Издевается, гад?») (Lenta.ru. 18.04.2018); «ботокс» («Ну все, докатились Валежник теперь будем собирать <...> Доуправлялся, ботокс :-(((») (Lenta.ru. 18.04.2018), «плешивая мразь» («Черт возьми, а вам не кажется, ребята, что вы давно превратились в тупое, бессловесное 6 ы д л о-сами стонете от этих диких, чудовищных запретов, а потом дружною толпой топаете на выборы и радостно выбираете эту плешивую м р а з в на новый срок?!!!!») (Lenta.ru. 18.04.2018), «святой плешивый педофил» («Ватань молитесь на икону святого плешивого педофила. Канонизировать Валотьку Акурка!») (Lenta.ru. 18.04.2018), «Плешивый» («Вот облегчение-то олигархам которых Плешивый подставил под санкции...»), «жид плешивый» («Жид плешивый, собирай свои вещи и вали к сатане в котел») (Lenta.ru. 18.04.2018).

Тему «власть» также представляют и другие компоненты, например, «Госдума», «власть», «Кремль» и др., но их упоминаний значительно меньше (15), чем упоминаний Владимира Путина. Президент и другие символы власти не противопоставляются друг другу, скорее, используются в качестве синонимов. Многие комментаторы их абсолютно не разделяют, например, пишут о Путине как о председателе правительства, хотя на самом деле эту должность занимает Дмитрий Медведев. Однако часть читателей все же видит разницу между, например, принятием (Госдума) и подписанием (президент) закона. 
Как следует из приведенных примеров, тему власти комментаторы в основном рассматривают в ироничном, саркастическом или негативном ключе, хотя имеются и противоположные мнения: положительные и нейтральные по отношению к политике - «а юридическое понятие слова валежник к закону прилагается?» (Lenta.ru. 18.04.2018).

Кроме политической элиты, с властью также соотносится закон - данное понятие довольно часто упоминается в комментариях к новости. В них закон представляется изначально серьезной силой, но обесцененной именно в РФ из-за его непостоянности и условности («Следующим законопроектом должен быть закон о разрешении россиянам беспрепятственно добывать еду из мусорных баков») (Lenta.ru. 18.04.2018). Также не раз отмечается отсталость российского законодательства и его постоянный запрещающий характер, в связи с чем разрешение на сбор валежника и произвело неожиданный эффект («Фигасе, сограждане. Да это же первый закон за 18 лет, когда что-то разрешить, а не запретить! Растем просто! Хотя его и так все собирали...») (Lenta.ru. 18.04.2018). Здесь мы видим отражение авторской оппозиции «серьезность - несерьезность».

Еще одной часто встречающейся словоформой является «народ» и сопряженные с ней «россияне», «русские», «население», «люди» («Какая царская щуедрость. Холопь должны радоваться, хотя русским надо спешить - дрова надо срочно собирать впереди ведь новые 90-е»; «Олигархам - миллиарды, а народу валежник») (Lenta.ru. 18.04.2018). Можно выделить оппозицию «власть - народ». Исходя из материала, она представляется следующим образом: элита показана несправедливой и жадной, в ее число входят чиновники и их приближенныемиллионеры / миллиардеры. Народ же выглядит угнетенным, все понимающим, но не предпринимающим никаких действий. Примером могут служить саркастические наименования народа, такие как «холопы», «чернь», «крепостная ватная скотина» («A $x a$ ха ха! Крепостной ватной скотине разрешили собирать ветки!!!») (Lenta.ru. 18.04.2018), «простой люд», «чиполлины», о чем мы упоминали выше, «россиянцы» («китай пол-тайги уже вырубил $u$ увозит, а росиянцам цүарской милостью валежник позволено собирать») (Lenta.ru. 18.04.2018), «расеяне». Причем, в представлении пользователей сайта, все ресурсы России принадлежат именно народу, в то время как власть их приватизировала, соответственно, президент не в праве ими 
распоряжаться. Как можно заметить, и в этом случае тактика автора оказывается успешной, в комментариях также просматривается дистанция между властью и народом.

Представляется возможным выделить еще одну оппозицию: «Россия - зарубежные страны». Особое внимание обращается на отношение российских властей к другим странам и населению РФ. Комментаторы отмечают, что для российской политической элиты приоритетнее поставить ценные природные ресурсы на Запад, чем отдать соотечественникам, поэтому народу «достаются» остатки, такие как валежник. В более негативном, чем Россия, свете предстает Украина («хохльг четыре года как трескают ежей в соусе и без..они пояснят как это...») (Lenta.ru. 18.04.2018).

Также страны сравниваются на основании законотворчества в сфере экологии в общем и лесного хозяйства в частности. Здесь некоторые комментаторы пытаются объяснить другим, что в более экономически развитых странах законы в этой сфере достаточно суровые, поэтому разрешение собирать валежник - это плюс российского законодательства и власти («Походу в штатах за куст марихуаны меньше дадут чем за морковку») (Lenta.ru. 18.04.2018). Но есть и те, кто, наоборот, приводит пример прогрессивности отдельных стран или всего мира, по сравнению с чем закон о сборе валежника выглядит нелепо («Штаты полет на Марс готовят, в России разрешают населению валежник собирать)...») (Lenta.ru. 18.04.2018).

Таким образом, мы видим, что большинство комментариев к новости «Путин подписал закон о свободном сборе валежника» на сайте Lenta.ru носят негативную оценку не столько нового закона, сколько российской власти вообще. Для ее выражения пользователи выбирают сарказм, иронию, грубо-просторечные слова, жаргонизмы и др.

Как мы видим, автор текста придерживается единой стратегии - стратегии дискредитации, однако реализует eе с помощью различных тактик: персонификации, «серого мира», низвержения и сокрытия, при этом применяя определенные речевые средства: он выбирает лексемы, подчеркивающие дистанцию между властью и народом, использует саркастические выражения и активный залог, подчеркивая ответственность президента РФ. Таким образом, можно сделать вывод, что стратегия и тактики автора новости влияют на мнение читателей: комментаторы реагируют на власть, персонифицируют ее в лице Владимира Путина, несмотря на то, что закон изначально принял не он. В ответной реакции сохраняется дистанция между властью и народом и между Россией (русскими) и 
другими странами, на это также наталкивает сама новость. Отметим, что большинство реакций было именно на сильные позиции текста (заголовок, лид и конец), лишь единицы обратили внимание на информацию, представленную в первом абзаце «тела новости».

На третьем этапе нашего исследования предполагается экспериментальная проверка зависимости читательских реакций от изменения текста данной новости (например, от изменения текстовых позиций, в которых представлена та или иная информация).

\section{Литература}

Быкова О.Н. К вопросу о языковой манипуляции в средствах массовой информации // Речевое манипулирование. М., 2012.

Гронская Н.Э. Язык и политика: коммуникация, дискурс, манипулирование. Нижний Новгород, 2005.

Доценко Е.Л. Психология манипуляции. Феномены, механизмы и защита. М., 1996.

Иванов Л.Ю. Нейролингвистическое программирование // Культура русской речи. М., 2003.

Иссерс О.С. Речевое воздействие. М., 2011.

Кара-Мурза С.Г. Манипуляция сознанием. М., 2001.

Копнина Г.А. Речевое манипулирование. М., 2012.

Куницына В.Н., Казаринова Н.В., Погольша В.М. Межличностное общение. СПб., 2001.

Лобанов А.А. Манипуляции в общении. Владимир, 1997.

Михалева О.Л. Политический дискурс: Специфика манипулятивного воздействия. М., 2009.

Пирогова Ю.К. Имплицитная информация как средство коммуникативного воздействия и манипулирования. На материале рекламных и PR-сообщений // Проблемы прикладной лингвистики. М., 2001.

Редькина Т.Ю. Активные лексико-семантические процессы в медиатексте // Филология и человек. 2013. № 2.

Сентенберг И.В., Карасик В.И. Псевдоаргументация: некоторые виды речевых манипуляций // Речевое общение и аргументация. СПб., 1993. Вып. 1.

Чикилева Л.С. Прагматический аспект предвыборных выступлений // Филология и человек. 2015. № 1.

Шейнов В.П. Искусство убеждать. М., 2000. М., 2001.

Шейнов В.П. Скрытое управление человеком (Психология манипулирования).

Язык СМИ и политика. Под ред. Г.Я. Солганика. М., 2012.

\section{Список источников}

Lenta.ru [Электронный ресурс]. URL: https://lenta.ru/news/2018/04/18/putin/ 


\section{References}

Bykova O.N. K voprosu o yazykovoy manipulyatsii $v$ sredstvakh massovoy informatsii [To the Issue of Language Manipulation in the Media]. Rechevoe manipulirovanie [Speech Manipulation]. Moskva, 2012.

Gronskaya N.E. Yazyk $i$ politika: kommunikatsiya, diskurs, manipulirovanie [Language and Politics: Communication, Discourse, Manipulation]. Nizhniy Novgorod, 2005 .

Dotsenko E.L. Psikhologiya manipulyatsii. Fenomeny, mekhanizmy $i$ zashchita [Psychology of Manipulation. Phenomena, Mechanisms and Protection]. Moskva, 1996.

Ivanov L.Yu. Neyrolingvisticheskoe programmirovanie [Neurolinguistic Programming]. Kul'tura russkoy rechi [Culture of Russian Speech]. Moskva, 2003.

Issers O.S. Rechevoe vozdeystvie [Speech Exposure]. Moskva, 2011.

Kara-Murza S.G. Manipulyatsiya soznaniem [Mind Manipulation]. Moskva, 2001.

Kopnina G.A. Rechevoe manipulirovanie [Speech Manipulation]. Moskva, 2012.

Kunitsyna V.N., Kazarinova N.V., Pogol'sha V.M. Mezhlichnostnoe obshchenie [Interpersonal Communication]. Sankt-Peterburg, 2001.

Lobanov A.A. Manipulyatsii $v$ obshchenii [Manipulation in Communication]. Vladimir, 1997.

Mikhaleva O.L. Politicheskiy diskurs: Spetsifika manipulyativnogo vozdeystviya [Political Discourse: Specificity of Manipulative Influence]. Moskva, 2009.

Pirogova Yu.K. Implitsitnaya informatsiya kak sredstvo kommunikativnogo vozdeystviya $i$ manipulirovaniya. Na materiale reklamnykh $i$ PR-soobshcheniy [Implicit Information as a Means of Communicative Influence and Manipulation. On the Material of Advertising and PR Messages]. Problemy prikladnoy lingvistiki [Problems of Applied Linguistics]. Moskva, 2001.

Red'kina T.Yu. Aktivnye leksiko-semanticheskie protsessy $v$ mediatekste [Active Lexical and Semantic Processes in the Media Text]. Filologiya i chelovek [Philology \& Human]. 2013. № 2.

Sentenberg I.V., Karasik V.I. Psevdoargumentatsiya: nekotorye vidy rechevykh manipulyatsiy [Pseudo-Argumentation: Some Types of Speech Manipulation]. Rechevoe obshchenie $i$ argumentatsiya [Speech Communication and Argumentation]. SanktPeterburg, 1993. Iss. 1.

Chikileva L.S. Pragmaticheskij aspekt predvybornykh vystuplenij [Pragmatic Aspect of Pre-Election Speeches]. Filologiya $i$ chelovek [Philology \& Human]. 2015. № 1.

Sheynov V.P. Iskusstvo ubezhdat' [Art of Persuading]. Moskva, 2000.

Sheynov V.P. Skrytoe upravlenie chelovekom (Psikhologiya manipulirovaniya) [Hidden Human Control (Psychology of Manipulation)]. Moskva, 2001.

Yazyk SMI i politika [Language of Media and Politics]. Pod red. G. Ya. Solganika. Moskva, 2012.

\section{List of sources}

Lenta.ru. URL: https://lenta.ru/news/2018/04/18/putin/ 